\title{
Paleopathology in the Piraino mummies as illustrated by X-rays
}

\author{
Dario PiombinO-MASCALi ${ }^{1 *}$, Albert R. ZINK ${ }^{2}$, Stephanie PANZER ${ }^{3}$ \\ ${ }^{1}$ Department of Biomedical and Dental Sciences and Morphological and Functional Imaging, University of Messina, Messina, Italy \\ ${ }^{2}$ European Academy, Institute for Mummies and the Iceman, Bolzano, Italy \\ ${ }^{3}$ Department of Radiology, Trauma Center Murnau, Murnau am Staffelsee, Germany
}

Received 9 May 2016; accepted 16 September 2016

\begin{abstract}
This paper presents the first radiological investigation of a collection of Sicilian mummies held in a crypt beneath the Mother Church of Piraino, Italy. The chamber contains 26 preserved bodies of religious dignitaries, either conserved vertically in special wall niches or horizontally on wooden shelves. The majority of bodies are clothed, and transportation outside of the crypt was not feasible. Therefore assessment of the remains via paleoradiological methods appeared to be the most convenient approach to investigate this precious ethno-anthropological heritage. Radiological examination of 23 of these mummies yielded information relating to their funerary treatment and some of the pathological alterations associated with the remains. These included osteoarthritis, diffuse idiopathic skeletal hyperostosis, and neoplasms, as well as any trauma present. These analyses provided insights into mortuary behavior and the osteobiographies of these clerical figures.
\end{abstract}

Key words: mummies, paleopathology, paleoradiology, cultural heritage, Italy

\section{Introduction}

In recent years, the understanding that mummified remains represent an important cultural heritage has grown considerably. There has been a realization that mummies should be treated as vitally important artifacts to be protected and preserved. Therefore, for many scholars involved in the field of mummy studies non-invasive techniques are imperative, as these avoid any permanent damage to such special assets (Lynnerup, 2007; Moissidou et al., 2015).

The mummies described in this paper come from the Sicilian town of Piraino, in the province of Messina, Italy (426 $\mathrm{m}$ above sea level), where an all-male sample of preserved bodies of clergymen is displayed in the Sepulcher of the Priests, a three-chambered vault located in the historic Mother Church (Figure 1). The burial place was founded by the archpriest, Giovanni Maria Antonio Scalenza, in 1771, with the support of the local clergy. Building of the tomb was carried out with the consent of Vincenzo Denti Colonna, the Prince of Castellazzo and Duke of Piraino and Alagona. The crypt is accessed by a staircase, situated in the proximity of the altar of Saint Bruna, virgin and martyr (Fornaciari et al., 2010). In the crypt 26 bodies are distributed across two rooms. Most lie horizontally on wooden shelves although two are standing upright in wall niches.

Archival sources revealed data for 23 subjects buried there between 1773 and 1858, all of whom were over 50

\footnotetext{
* Correspondence to: Dario Piombino-Mascali, University Hospital, Via Consolare Valeria 1, 98125 Messina, Italy.

E-mail: dario.piombino@unime.it

Published online 23 December 2016

in J-STAGE (www.jstage.jst.go.jp) DOI: 10.1537/ase.160916
}

years of age when they died. Currently, only one of the 26 bodies is still identifiable. This mummy belongs to Antonio Messina, who died in 1789, aged 69 (Piraino Parish Archive, unpublished data). Because removal of the mummies from their location was not possible, the use of a portable X-ray device was the only technique available to gain new knowledge of these remains, of their mummification process, and most importantly of the diseases from which they suffered (Aufderheide, 2003).

\section{Materials and Methods}

Within the framework of the Sicily Mummy Project, 23 mummies were examined using a mobile digital radiography system (Dragon DR, CXDI-50G, Canon/Sedecal) that was assembled inside the crypt (Piombino-Mascali et al., 2011). Three of the bodies were left out of the investigation due to safety concerns. The protocol employed has been previously described elsewhere (Piombino-Mascali et al., 2015). Most of the mummies investigated in this research still wore their religious attire, as well as a form of legging in 11 cases and shoes in one case. The heads of the supine bodies lay on one or more terracotta tiles, or sometimes on pillows placed on top of a tile. Seven bodies wore caps, while eight caps were located next to or on top of the related corpses. Despite being mostly covered by clothes, the bodies revealed soft tissue preservation, with the exception of one case that was almost completely skeletonized. External genitalia could be inspected in 12 cases, and one specimen bore evidence of a possible inguinoscrotal hernia. Additionally, age at death was roughly established based on dental wear and cranial suture closure (Cox and Mays, 2000). This revealed an alladult sample. 


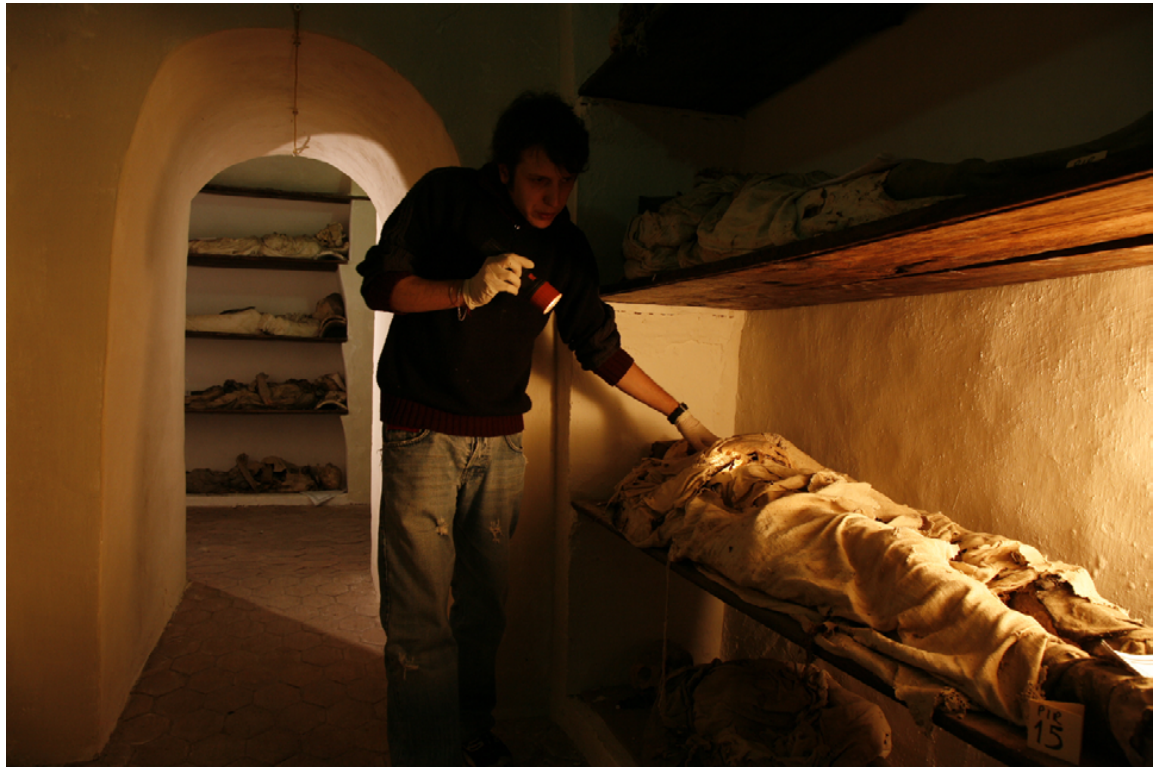

Figure 1. The crypt of Piraino during a recent inspection of the mummies. Access to this crypt was covered by new flooring in the years 1933-1934 and was officially reopened by 1994.

Paleoradiology is the study of ancient mummies, skeletal remains, and fossils using radiological imaging methods. These methods include X-ray, computed tomography, and magnetic resonance imaging (Chhem and Brothwell, 2008; Beckett, 2014). Despite its possible limitations, which may include blurring of the images and contrast reduction (Wanek et al., 2011), plain radiography has often been adopted as a basic tool for mummy examination (Lynnerup, 2007; Lynnerup and Rühli, 2015). It has the advantage of being affordable, accessible, and mobile, offering the opportunity for remains to be studied on site, often in very remote locations (Notman et al., 1987). In addition, conventional radiographs have gained increasing value due to recent technological innovations. These innovations include high spatial resolution, full digitalization, and the possibility to visualize improved soft tissue discrimination (Panzer et al., 2010; Kristóf et al., 2015).

While the investigation of the mummy sample concerned provides information on the mummification process, its main focus was to assess the presence of disease in these individuals and attempt to relate this to lifestyle and behavior.

\section{Results}

Firstly, the X-ray investigation did not reveal evidence of post-mortem incisions or other manipulations. The images illustrated preservation of the ligaments and tendons in 21 of the mummies, detectable as relatively dense structures in their anatomical position, at times shrunken due to dehydration. These included the rotator cuff, the quadriceps and patellar ligament, the meniscus, the Achilles tendon, and the plantar fascia. Dense structures in the posterior cranial fossa, thought to be remnants of brain, were observed in those mummies that were supine (Figure 2).

Regarding indications of pathological conditions, we observed that the vast majority of mummies bore evidence of degenerative joint disease, in the form of subchondral sclerosis and cyst formation, osteophytes of different size, and irregular contours of the articular surfaces. This condition affected the spine of 21 subjects, in two cases severely. Evidence of osteoarthritis was also found in the sacroiliac joint and pubic symphysis of nine subjects, while some of them showed the disease in the hip, knee, ankle, patellofemoral joint, or shoulder. Nine bodies revealed the presence of cal-

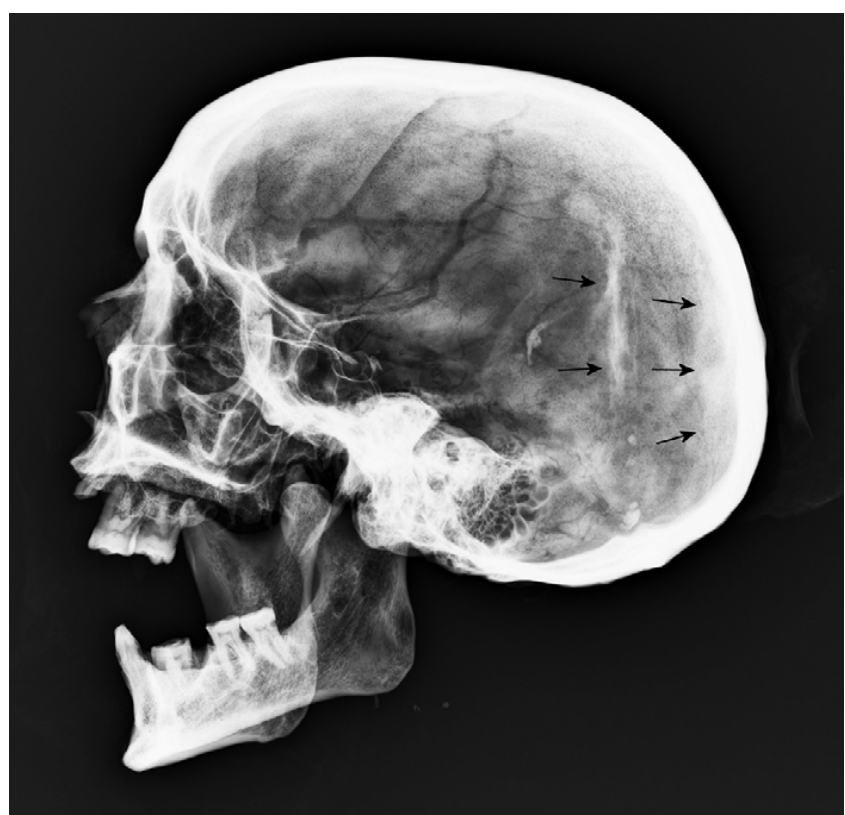

Figure 2. Probable remnants of brain tissue in Piraino 20. The lateral radiograph of the skull shows a dense area at the dorsal-most part of the skull in the mummy and another dense area above (arrows), which are thought to represent remains of dried colliquated brain tissue. The mandible is dislocated and some teeth have been lost. 


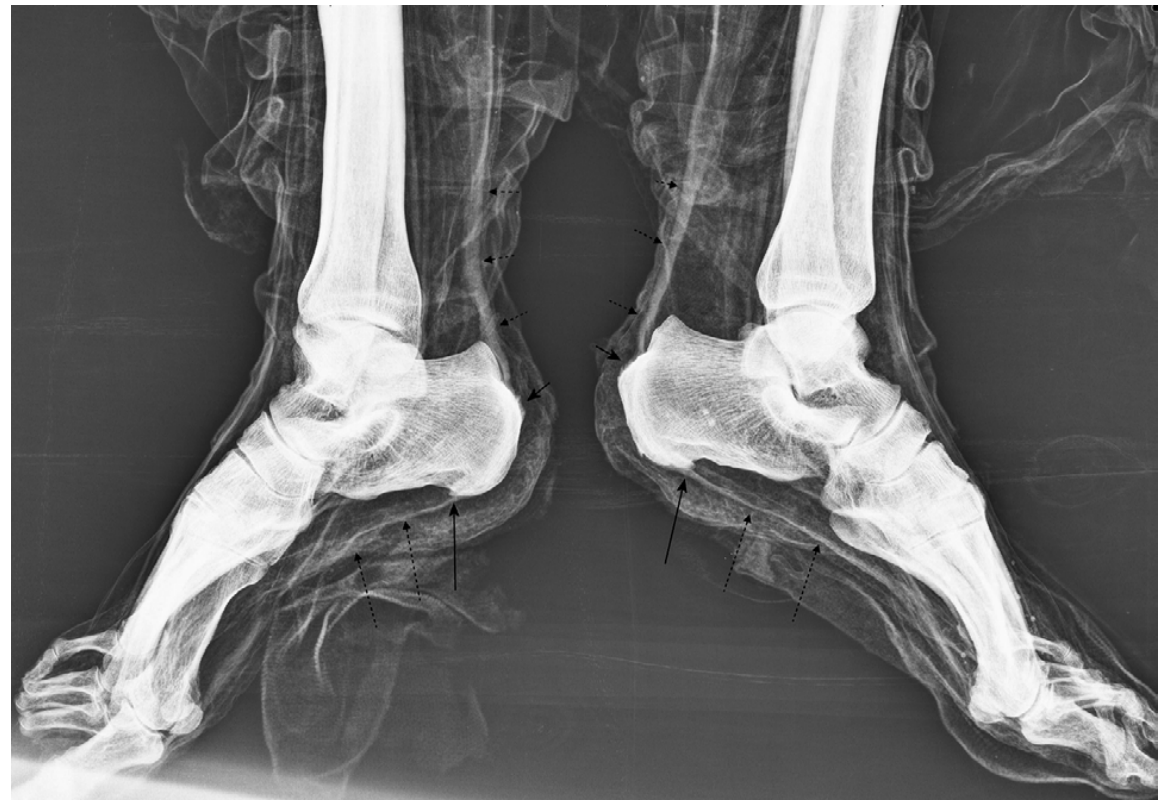

Figure 3. Calcaneal spurs in Piraino 15. The lateral radiograph of the feet demonstrates bilateral spurs at the insertion of the plantar fascia (long arrows) and the Achilles tendon (short arrows). Note the bilateral preservation of the plantar fascia (long dotted arrows) and the Achilles tendon (short dotted arrows).

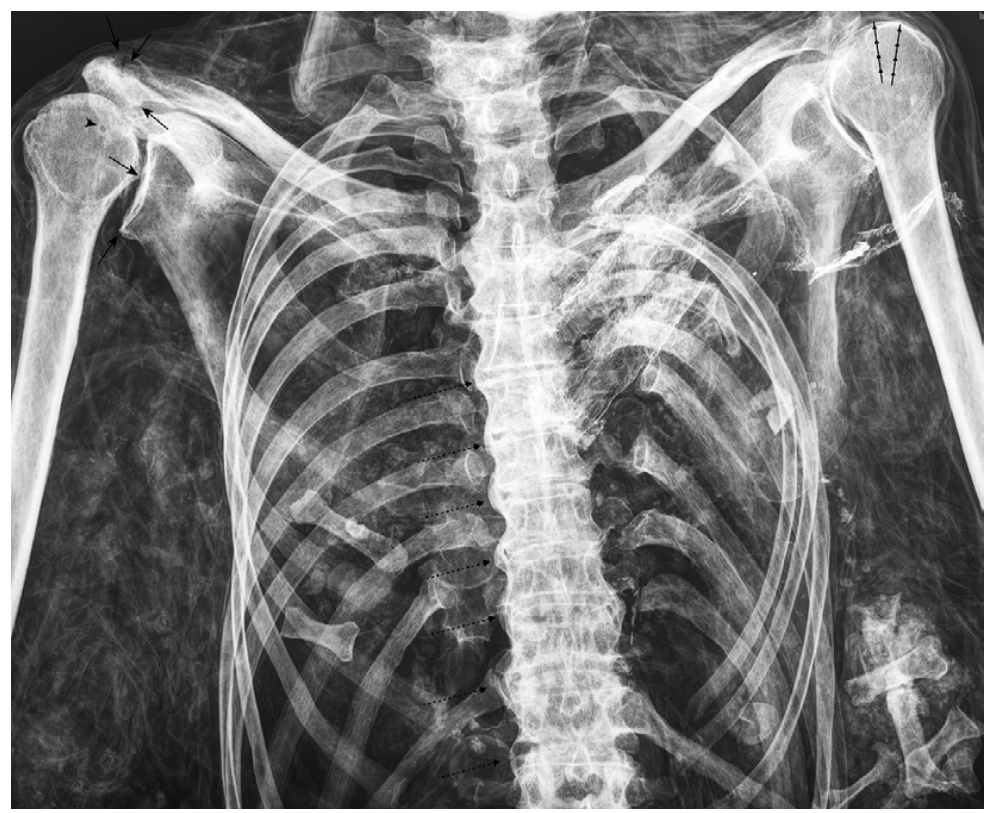

Figure 4. Osteoarthritis and DISH in Piraino 10. The anteroposterior radiograph of the chest illustrates flowing ossifications along the right lateral aspect of the thoracic spine (dotted arrows). The intervertebral spaces are relatively preserved. On the right shoulder, osteophytes are visible in the acromioclavicular joint as well as the humeral head and the inferior glenoid fossa (short arrows). Note the irregular contours of the glenohumeral articular surfaces and a small cystic lesion in the humeral head (arrowhead). Parts of the rotator cuff are preserved on the left side (arrowlines). Note the superimposition by the small bones of the hands and clothes as well as the post-mortem dislocations.

caneal spurs of different size, located at the insertion of the plantar fascia and the Achilles tendon (Figure 3). Two subjects showed changes compatible with a diagnosis of diffuse idiopathic skeletal hyperostosis (DISH), indicated by flowing ossifications along the lateral and anterior aspect of the thoracic spine, but sparing of the intervertebral spaces (Fig- ure 4; Figure 5).

Evidence of trauma was also observed, in the form of healed rib and vertebral fractures, affecting as many as four individuals (Figure 6).

Additionally, one case appears to have been affected by atherosclerosis in the form of small, predominantly linear 


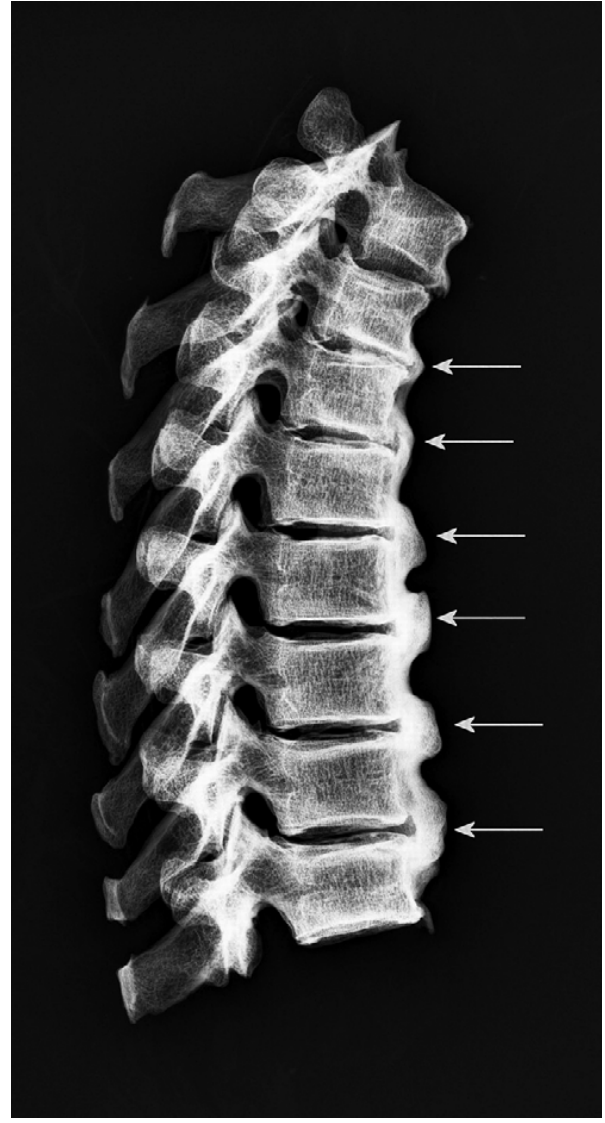

Figure 5. DISH in Piraino 19. The lateral radiograph of parts of the skeletonized thoracic spine illustrates the typical flowing ossifications along the anterior aspect of the spine (arrows) over four adjoining vertebral bodies. The facet joints are not fused and the intervertebral spaces are preserved.

calcifications at the margins of the femoral arteries (Figure 7). Neoplasms, most of which were likely benign in nature, were also noted in the sample and included a case of calcifying enchondroma located in the left distal femur of a mummy. This was represented by a lobulated lesion associated with anular, punctate, and comma-shaped calcifications in the matrix, as well as the lack of a sclerotic rim (Figure 8). An additional subject also showed a lesion that might be an enchondroma, although a medullary bone infarct could not be ruled out in either case. To these can be added a small osteoma that was identified on the frontal sinus of a mummy. One of these individuals showed multiple osteolytic lesions of different size in the ribs, the humeri, the right pubic bone, and possibly both femora and the right scapula, indicating a malignancy (Figure 9). The skull revealed a prominent diploic vascular pattern with venous lakes as well as pacchionian granulations. A few additional osteolytic lesions might also be present. From the resulting radiographs, however, a clear discrimination between the most probable differential diagnoses of multiple osteolytic metastases and multiple myeloma was not possible.

Furthermore, we observed only one deformity, which is a case of hallux valgus (Figure 10); anatomical variants included a sternum with a foramen and a supernumerary cervi-

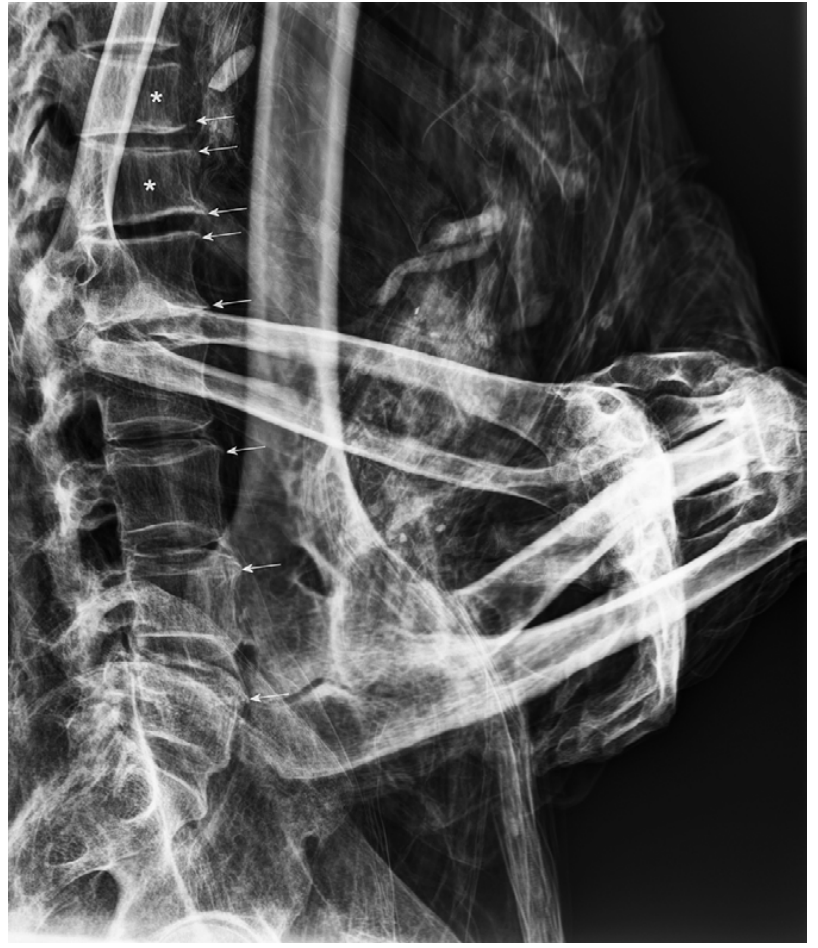

Figure 6. Healed vertebral fractures in Piraino 6. The lateral radiograph of the lower spine shows a decrease in the height of the 11th and 12th thoracic vertebrae in the anterior part, secondary to compression fractures (asterisks). Persistent fracture lines are not detectable, indicating complete osseous healing. Note the osteophytes of both fractured vertebrae and of the lumbar spine (arrows) showing arthritic changes.

cal rib on the left side of a mummy (Figure 11). With regard to the dental status, cases of dental infection, enamel defects, and bone resorption, as well as cases of intravital tooth loss, were recorded. Finally, post-mortem dislocations were observed in 20 of the specimens, and post-mortem fractures were encountered in two cases.

\section{Discussion}

In Sicily and the south of Italy, the process of mummification was a widespread phenomenon, conceived to preserve the social persona of important, distinguished individuals, religious figures, and middle-class citizens (Farella, 1982; Piombino-Mascali, 2015; Piombino-Mascali et al., 2010, 2015). This required dehydration of cadavers in specifically designed structures, most commonly located inside the crypts. There, bodies were laid on terracotta or wooden racks or positioned on seats that might be built into wall niches. These methods achieved mummification of the tissues. Only at the end of this process was the body cleaned, dressed and displayed in a wall niche or coffin. Accordingly, no evidence of incisions or other manipulations was evident in the sample investigated, confirming that the Piraino mummies were spontaneously mummified (Aufderheide, 2003).

In Piraino, the draining facility is formed by a narrow, vertical, rectangular room provided with a basin and a drainpipe for gathering of the cadaveric fluids. Two masonry 


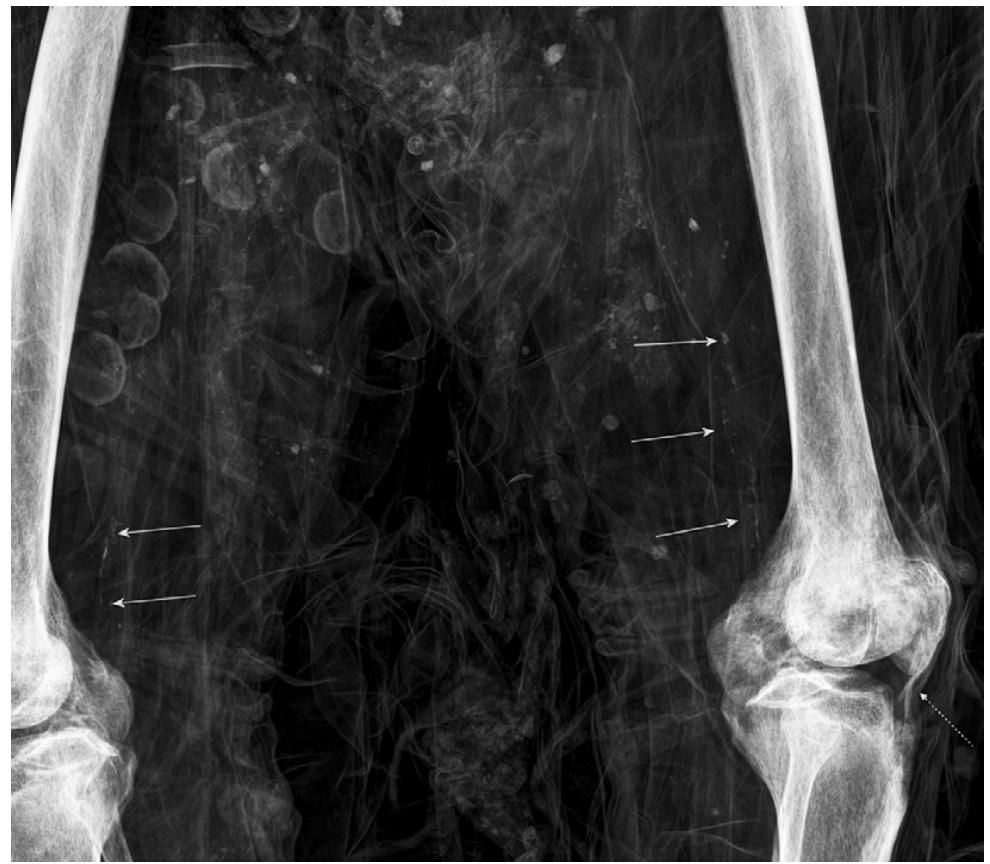

Figure 7. Atherosclerosis in Piraino 20. The anteroposterior radiograph of both thighs and knees shows subtle calcifications of the distal superficial femoral artery in both legs (arrows). Preservation of the patellar ligament is seen on the left side (dotted arrow). Note the superimposition by textiles and organic materials such as nutshells.

benches along the short sides of this small room acted as a support for a wooden rack, still extraordinarily preserved, upon which corpses were laid to mummify (Fornaciari et al.,

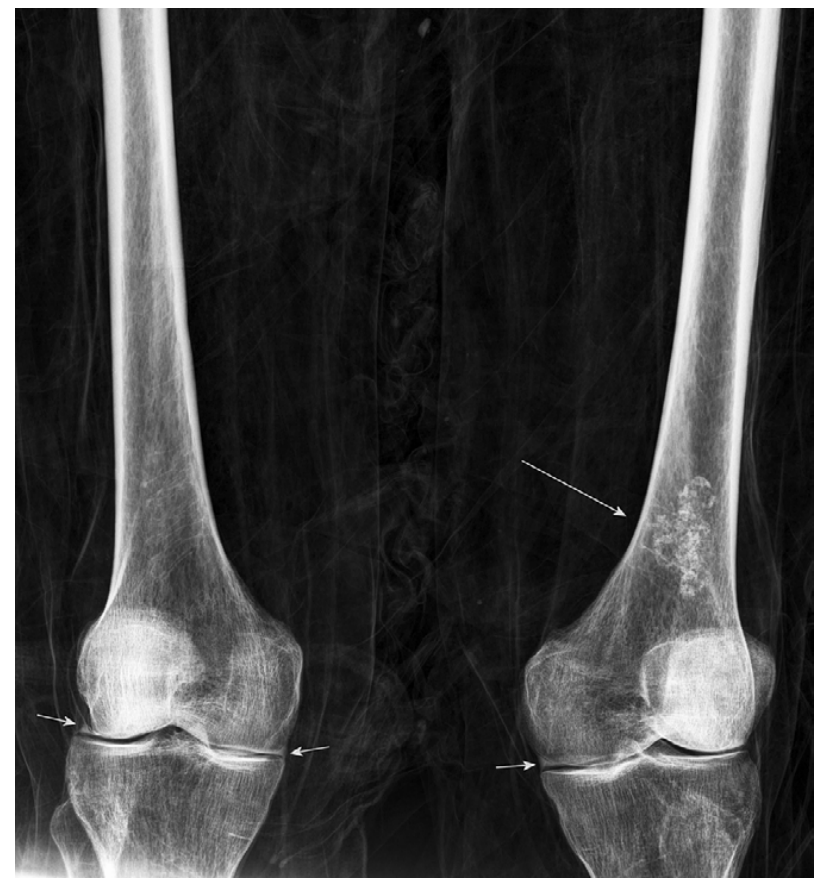

Figure 8. Calcifying enchondroma in Piraino 6. The anteroposterior radiograph of both thighs and knees demonstrates chondroid calcifications in the left distal femur with lobular appearance indicating enchondroma (long arrow). There appears to be preservation of the medial meniscus in both knees and preservation of the lateral meniscus on the right side as sharply bordered dense structures (short arrows).
2010). This room could be closed with a door made of slate, still observable inside the crypt. Historical sources state that the bodies drained for as long as two months as part of the mummification process (Piraino Parish Archive, unpublished data).

Although naturally mummified, 19 of the cases revealed some form of packing of the body cavities with vegetal elements or fragments of fabric. It is probable that these were added via areas of natural decay subsequent to the desiccation process. Botanical analyses were performed to identify pollen, seeds, leaves, and stems. These analyses identified plants used for their preservative properties, as well as plants belonging to the Mediterranean flora present in the landscape surrounding the church (Piombino-Mascali et al., 2013a). These comprised: ivy, cypress, juniper, sage, rosemary, and lemon, to name but a few.

The most common pathological condition observed in as many as 21 individuals and linked to social status is degenerative joint disease, which is caused by the loss of joint cartilage and consequent lesions resulting from bone-onbone contact, with subsequent sclerosis and eburnation (Waldron, 2009). With regard to this condition, typical features visible on radiographs consist of subchondral cysts, subchondral sclerosis, and osteophytes of the various joints. The feature of joint space narrowing is not applicable to paleoradiology as soft tissues and joint alignments are affected post-mortem in mummies (Chhem and Brothwell, 2008). The differential diagnosis of inflammatory arthritisincluding, amongst other conditions, rheumatoid arthritis as a seropositive subtype and ankylosing spondylitis as a seronegative subtype - can be distinguished on radiographs via articular erosions, bony ankyloses, or periosteal reactions on the limb joints. In the spine, inflammatory arthritis is indicat- 


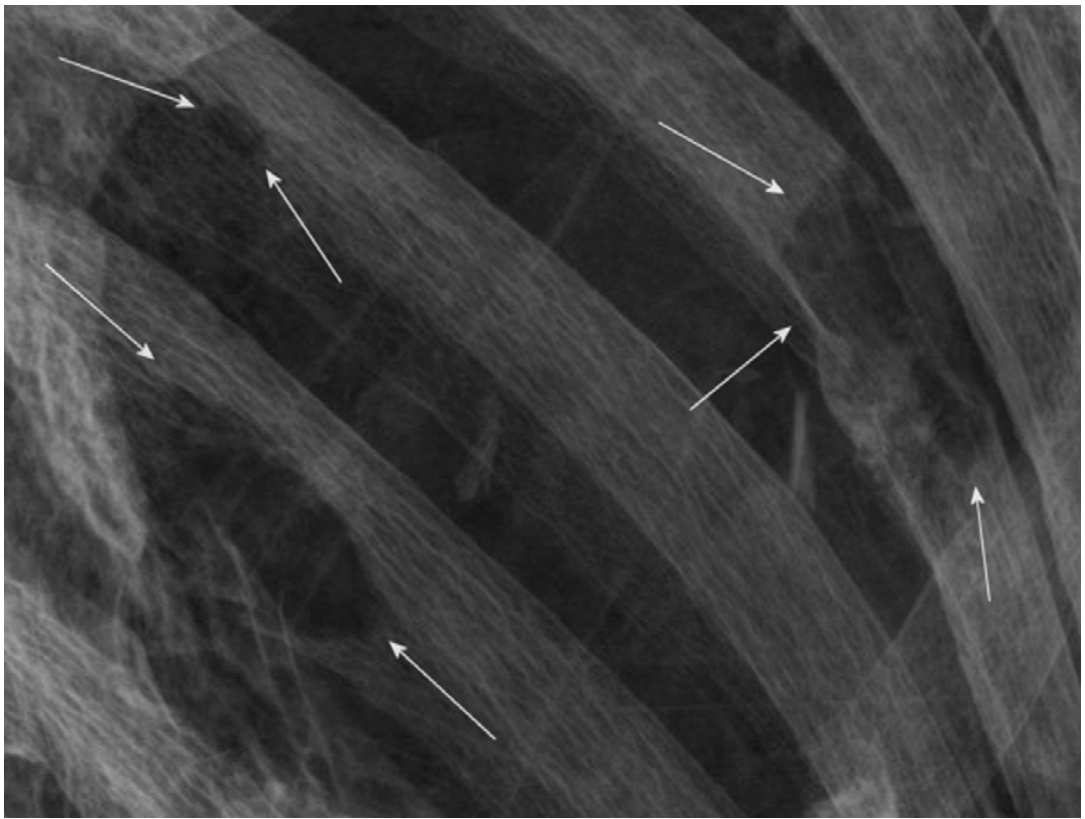

Figure 9. Osteolysis in Piraino 1. Detail from the anteroposterior radiograph of the chest illustrating distinct osteolytic lesions of different size in the 8th, 9 th, and 10th ribs of the left hemithorax (arrows), which is consistent with osteolytic metastases or multiple myeloma.

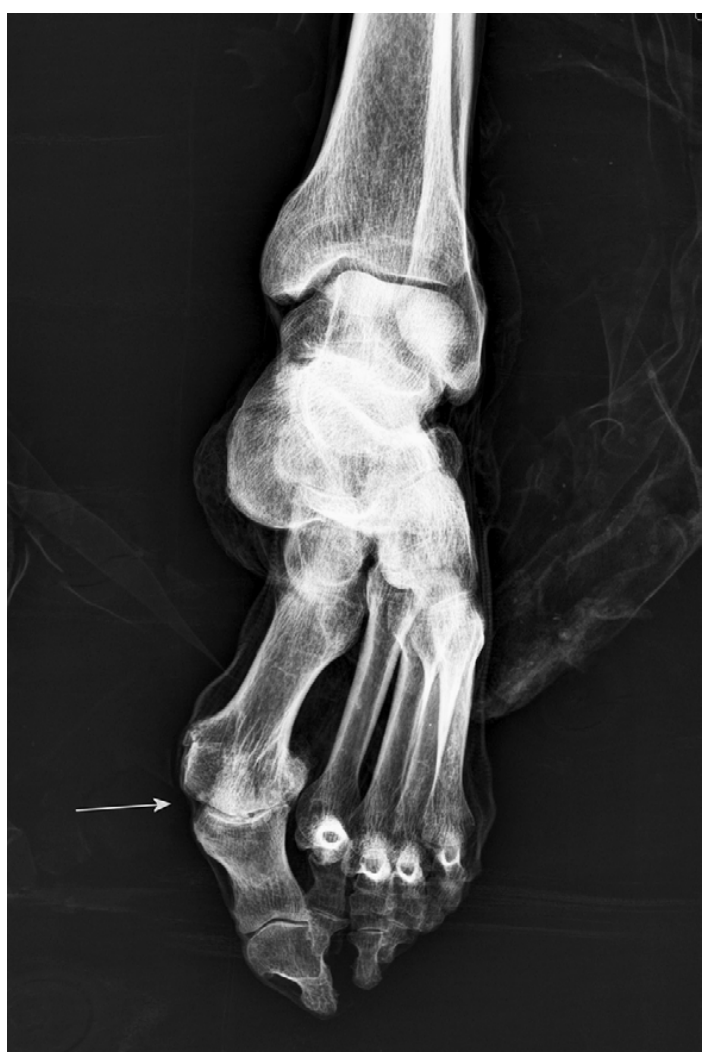

Figure 10. Hallux valgus in Piraino 4. The anteroposterior radiograph of the left foot demonstrates a malaligned axis of the metatarsophalangeal joint of the first toe with lateral deviation of the phalanx and metatarsus primus varus resulting in valgus deformity (arrow). Note the slight arthritic changes in the medial aspect of the joint. ed by the presence of syndesmophytes and parasyndesmophytes, which are identified as thin ossifications between the vertebral bodies with vertical growth and as squaring of the vertebral bodies (Chhem and Brothwell, 2008; Resnick, 2002). Degenerative joint disease is the most common form of bone pathology and may in some cases be diagnosed before the fourth decade of life, progressing with age and with no sex predilection (Aufderheide and Rodríguez-Martín, 1998). Although the etiology of this condition in past populations is difficult to determine, it is tempting to believe that in the case of Piraino, many of the lesions observed are mostly related to the advanced age of the subjects, who may have enjoyed a longer life because of their high social status. This interpretation finds support from a similar investigation of the Savoca mummies, another Sicilian site where 15 out of the 16 subjects investigated showed evidence of osteoarthritis (Piombino-Mascali et al., 2015).

Of note is also the presence of bony spurs on the heel bones of nine individuals, defined as enthesopathies in the context of inflammatory arthritis, which are sometimes related to activities such as running or standing on the toes (Capasso et al., 1999; Chhem and Brothwell, 2008).

An additional condition that may be linked to social status is DISH, a systemic disorder first identified in the mid-20th century (Forestier and Rotes-Querol, 1950). The main feature of DISH is the tendency to produce exuberant bone growth at the joint margins and the extraspinal entheses, notably under the anterior longitudinal ligament of the spine, with a typical 'dripping candle wax' appearance (Aufderheide and Rodríguez-Martín, 1998). Although the whole spine may be involved, the condition only affects the right side at the thoracic level due to the presence of the descending aorta on the left side of the vertebral column. DISH can be diagnosed when more than four vertebrae are fused, though some 


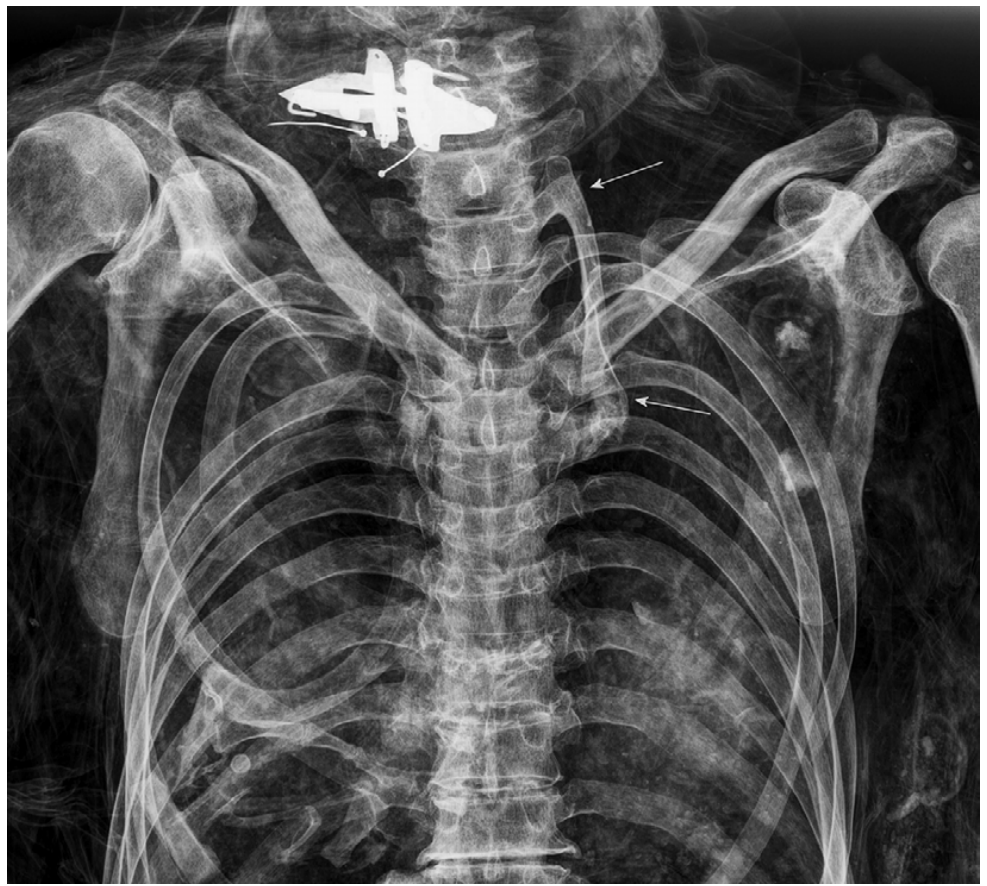

Figure 11. Cervical rib in Piraino 25. The anteroposterior radiograph of the chest demonstrates a large cervical rib on the left side (arrows). It starts from the 7th cervical vertebra with synostosis to the transverse process and reaches the sternum. In this large development, the cervical rib is similar to a true rib in terms of size and shape. Note the superimposition by a clerical collar in the region of the neck and the post-mortem dislocation of some ribs.

authors consider three vertebrae as sufficient to diagnose an early phase of the condition (Waldron, 2009). The ossification of the spine leads to ankylosis of the involved vertebrae, but spares the intervertebral disc spaces and the apophyseal joints (Aufderheide and Rodríguez-Martín, 1998). From a clinical viewpoint, DISH rarely appears before the fourth decade of life and affects mostly males. Of note is the fact that the condition can be associated with metabolic disorders, including obesity and type-2 diabetes mellitus (SarziPuttini and Atzeni, 2004). Paleopathological studies indicate a link between high social status and the risk of developing DISH. Examples include two members of the Medici family of Florence, Prince Luigi Carafa di Stigliano, the bishop of Alghero, Eliseo Giordano, as well as three cases from the aforementioned Savoca crypt (Fornaciari, 2006; Fornaciari and Lunardini, 2003; Fornaciari et al., 2009; Giuffra et al., 2010). The cases of DISH reported in this article seem to confirm the association between the onset of this condition and elite status, which would have implied privileged eating habits.

Atherosclerosis, supposedly evidenced in one of the investigated mummies, is a multifactorial disease involving both genetic and environmental factors (Aufderheide and Rodríguez-Martín, 1998; Singh et al., 2002). It is characterized by accumulation of cholesterol, infiltration of macrophages, proliferation of smooth muscle cells, and accumulation of connective tissue components within the intima of medium- and large-sized blood vessels, which eventually form an occlusion that can result in coronary heart and cerebrovascular disease (Singh et al., 2002; Falk, 2006; Slijkhuis et al., 2009). In recent studies, this condition has been the subject of investigation in mummified remains. In particular, to assess whether atherosclerosis was a condition dependent on the lifestyle of Egyptian elites or if it was also encountered in ancient populations with different subsistence strategies (Allam et al., 2009, 2011; Thompson et al., 2013). Studies have demonstrated atherosclerosis in other prehistoric and historic mummies, including the chalcolithic Iceman, a mummy from the Joseon dynasty, and a pre-agricultural hunter-gatherer population from the Aleutian Islands (Murphy et al., 2003; Abdelfattah et al., 2013; Thompson et al., 2013; Kim et al., 2015). While research seems to indicate that atherosclerosis is an inherent component of the aging process (Thompson et al., 2013), it is undeniable that it some cases, such as the mummies from Vilnius, Lithuania, diet and behavior must have played a role (Piombino-Mascali et al., 2014).

The described osteolytic changes seen in one of the Piraino bodies are compatible with the diagnosis of multiple myeloma or skeletal metastasis (Steinbock, 1976; Resnick, 2002; Ortner, 2003), further testifying to the presence of cancer among pre-industrial societies (Capasso, 2005). In fact, very few cancer cases have so far been diagnosed in Italian mummies (Fornaciari et al., 1999). This example appears to be particularly relevant, as in addition to the bone changes, other studies revealed important details. Microscopic investigation discovered several thousand Trichuris trichiura eggs, recovered from a coprolite that was obtained from the abdomen. This indicates that the subject suffered from parasitic infestation (Kumm et al., 2010). Moreover, botanical analyses determined that much of the pollen contained in the coprolite came from a species of Polygala, a 
plant historically employed for therapeutic purposes (Piombino-Mascali et al., 2013b). This evidence was suggestive of the consumption of an infusion, in other words foliage or flowers dispersed in water that was strained of large particles and drunk. Therefore, medicinal preparations could have included pollen that was consumed by this subject specifically for his symptoms, thus providing evidence of ancient care (Tilley and Cameron, 2014).

The supernumerary cervical rib is a relatively common anatomical variant. However, it is of clinical interest in that it can cause a thoracic outlet syndrome that may provoke discomfort and pain (Viertel et al., 2012). Because of the large size in this specific case, it is possible that the subject experienced symptoms due to compression of the lower brachial plexus or the subclavian artery, which may have included brachyalgia, paresthesia, paresis, and peripheral circulation disorder. However, it is accepted by many in the medical profession that symptoms are more common when the cervical rib is small and accompanied by an uncalcified scalene band.

The anatomical malposition known as hallux valgus is worth mentioning. A deviation of the big toe, bunion was already noted in the Savoca mummies, and some believe that this might be associated with the use of pointed shoes (Piombino-Mascali et al., 2015). Finally, the dental status of these subjects suggests poor dental hygiene (Chhem and Brothwell, 2008; Scheinfeld et al., 2012).

\section{Limitations}

As is often the case when dealing with mummies, limitations were also encountered during the Piraino mummy investigation (Lynnerup and Rühli, 2015). These included superimposition by clothes, stiffness or fragility of the remains, as well as difficulties in discriminating soft tissue. Furthermore, a more precise age estimation was deemed impossible in the vast majority of cases, due to the fact that soft tissue and clothes were covering anthroposcopic areas.

\section{Conclusions}

The X-ray investigation of the Piraino mummies has proved useful for assessing the presence of bone pathologies which would not have been seen otherwise due to the presence of soft tissues and clothes covering the bony elements. Many conditions demonstrated by this investigation, combined with contextual data, were vital in providing insights on life quality and behavior within the Piraino population. Despite its limitations, conventional radiology remains a fundamental tool for a non-invasive investigation of preserved remains, helping reconstruct mortuary customs and identify bone pathologies.

\section{Acknowledgments}

We are most grateful to Father Calogero Musarra, archpriest of Piraino, as well as to Mario Sergio Todesco, former head of the Ethno-anthropological Division, Superintendence of the Cultural and Environmental Heritage of Messina, for advocating this project. Thanks are also due to Elena
Kranioti, Linda Fibiger, and Kenneth Nystrom for helpful comments. The Sicily mummy expedition was generously supported by a grant of the National Geographic Expedition Council, awarded to the first author of this study (\#ECO 38 $1-08)$.

\section{References}

Abdelfattah A., Allam A.H., Wann S., Thompson R.C., AbdelMaksoud G., Badr I., Amer H.A., Nurledin H., Finch C., Miyamoto M.I., Sutherland M.L., Sutherland J.D., and Thomas G.S. (2013) Atherosclerotic cardiovascular disease in Egyptian women: 1570 BCE-2011 CE. International Journal of Cardiology, 167: 570-574.

Allam A.H., Thompson R.C., Wann S.L., Miyamoto M.I., and Thomas G.S. (2009) Computed tomographic assessment of atherosclerosis in ancient Egyptian mummies. Journal of the American Medical Association, 302: 2091-2094.

Allam A.H., Thompson R.C., Wann L.S., Miyamoto M.I., Nur ElDin Ael-H., El-Maksoud G.A., Al-Tohamy Soliman M., Badr I., El-Rahman Amer H.A., Sutherland M.L., Sutherland J.D., and Thomas G.S. (2011) Atherosclerosis in ancient Egyptian mummies: the Horus study. Journal of American College of Cardiology, 4: 315-327.

Aufderheide A.C. (2003) The Scientific Study of Mummies. Cambridge University Press, Cambridge.

Aufderheide A.C. and Rodríguez-Martín C. (1998) The Cambridge Encyclopedia of Human Paleopathology. Cambridge University Press, Cambridge.

Beckett R. (2014) Paleoimaging: a review of applications and challenges. Forensic Science Medicine and Pathology, 10: 423436.

Capasso L. (2005) Antiquity of cancer. International Journal of Cancer, 113: 2-13.

Capasso L., Kennedy K.A.R., and Wilczac C.A. (1999) Atlas of Occupational Markers on Human Remains. Edigrafital, Teramo.

Chhem R.K. and Brothwell D.R. (2008) Paleoradiology. Imaging Mummies and Fossils. Springer-Verlag, Berlin.

Cox M. and Mays S. (2000) Human Osteology in Archaeology and Forensic Science. Cambridge University Press, Cambridge.

Falk E. (2006) Pathogenesis of atherosclerosis. Journal of the American College of Cardiology, 47: C7-12.

Farella F.D. (1982) Cenni storici della Chiesa e delle Catacombe dei Cappuccini di Palermo. Fiamma Serafica, Palermo.

Forestier J. and Rotes-Querol J. (1950) Senile ankylosing hyperostosis of the spine. Annals of the Rheumatic Diseases, 9: 321330.

Fornaciari A. and Lunardini A. (2003) Indagine paleopatologica sui resti scheletrici del vescovo di Alghero Eliseo Giordano (1820-1906). Archeologia Postmedievale, 7: 267-270.

Fornaciari A., Giuffra V., and Pezzini F. (2010) Secondary burial and mummification practices in the Kingdom of the two Sicilies. Mortality, 15: 223-249.

Fornaciari G. (2006) Le mummie aragonesi in San Domenico Maggiore di Napoli. Medicina nei Secoli Arte e Scienza, 18: 843864.

Fornaciari G., Marchetti A., Pellegrini S., and Ciranni R. (1999) K-ras mutation in the tumour of King Ferrante I of Aragon (1431-1494) and environmental mutagens at the Aragonese court of Naples. International Journal of Osteoarchaeology, 9: 302-306.

Fornaciari G., Giuffra V., Giusiani S., Fornaciari A., Villari N., and Vitiello A. (2009) The 'gout' of the Medici, Grand Dukes of Florence: a palaeopathological study. Rheumatology, 48: 375-377.

Giuffra V., Giusiani S., Fornaciari A., Villari N., Vitiello A., and Fornaciari G. (2010) Diffuse idiopathic skeletal hyperostosis 
in the Medici, Grand Dukes of Florence (XVI century). European Spine Journal, 19 Supplement 2: 103-107.

Kim M.J., Kim Y.-S., Oh C. S., Go J.-H., Lee I.S., Park W.-K, Cho S.-M., Kim S.-K., and Shin D.H. (2015) Anatomical confirmation of computed tomography-based diagnosis of the atherosclerosis discovered in 17 th century Korean mummy. PLoS ONE, 10: e0119474.

Kristóf L.A., Kovács M., Baksa G., Bereczki Z., Szatmári F., Patonay L., Pálfi G., and Pohárnok L. (2015) Condition assessment of two early Christian martyrs', St Christine's and St Augustine's relics with paleoradiological methods in Hungary. Journal of Cultural Heritage, 16: 249-253.

Kumm K., Reinhard K.J., Piombino-Mascali D., and Araújo A. (2010) Archaeoparasitological investigation of a mummy from Sicily (18th-19th century AD). Anthropologie, 48: $177-184$

Lynnerup N. (2007) Mummies. Yearbook of Physical Anthropology, 50: 162-190.

Lynnerup N. and Rühli F. (2015) The use of conventional X-rays in mummy studies. Anatomical Record, 298: 1085-1087.

Moissidou D., Day J., Shin D.H., and Bianucci R. (2015) Invasive versus non invasive methods applied to mummy research: will this controversy ever be solved? BioMed Research International, article ID 192829.

Murphy W.A. Jr, zur Nedden D., Gostner P., Knapp R., Recheis W., and Seidler H. (2003) The Iceman: discovery and imaging. Radiology, 226: 614-629.

Notman D.N.H., Anderson L., Beattie O.B., and Amy R. (1987) Arctic paleoradiology: portable radiographic examination of two frozen sailors from the Franklin expedition (1845-1848). American Journal of Roentgenology, 149: 347-350.

Ortner D.J. (2003) Identification of Pathological Conditions in Human Skeletal Remains, 2nd edn. Academic Press, San Diego.

Panzer S., Zink A.R., and Piombino-Mascali D. (2010) Radiologic evidence of anthropogenic mummification in the Capuchin Catacombs of Palermo, Sicily. RadioGraphics, 30: 11231132.

Piombino-Mascali D. (2015) Capuchin Catacombs of Palermo. In: Cardin M. (ed.), Mummies around the World: An Encyclopedia of Mummies in History, Religion, and Popular Culture. ABC-Clio, Santa Barbara, pp. 51-53.

Piombino-Mascali D., Aufderheide A.C., Panzer S., and Zink A.R. (2010). Mummies from Palermo. In: Wieczorek A. and Rosendahl W. (eds.), Mummies of the World. The Dream of Eternal Life. Prestel, New York, pp. 357-361.

Piombino-Mascali D., Panzer S., Marvelli S., Lösch S., Aufderheide A.C., and Zink A.R. (2011) The "Sicily Mummy Project": first results of the scientific campaigns (2007-2010). In: Sörries R. (ed.), Kasseler Studien zur Sepulkralkultur, Vol. 18: Geschichte und Tradition der Mumifizierung in Europa. Arbeitsgemeinschaft Friedhof und Denkmal eV, Kassel, pp. 25-31.

Piombino-Mascali D., Zink A., and Marvelli S. (2013a) Un approccio paleobotanico alla storia della conservazione dei corpi nella Sicilia di Età Moderna. Rivista di Storia della Medicina, 23: $125-143$.
Piombino-Mascali D., Zink A.R., Reinhard K.J., Lein M., Panzer S., Aufderheide A.C., Rachid R., De Souza W., Araújo A. Chaves S.A.M., LeRoy-Toren S., Teixeira-Santos I., and Dutra J.M.F. (2013b) Dietary analysis of Piraino 1: The role of archaeopalynology in forensic science. Journal of Archaeological Science, 40: 1935-1945.

Piombino-Mascali D., Jankauskas R., Tamošiūnas A., Valančius R., Thompson R.C., and Panzer S. (2014) Atherosclerosis in mummified human remains from Vilnius, Lithuania (18th19th centuries $\mathrm{AD}$ ): a computed tomographic investigation. American Journal of Human Biology, 26: 676-681.

Piombino-Mascali D., Jankauskas R., Zink A.R., Todesco M.S., Aufderheide A.C., and Panzer S. (2015) Paleoradiology of the Savoca mummies, Sicily, Italy (18th-19th centuries AD). Anatomical Record, 298: 988-1000.

Resnick D. (2002) Diagnosis of Bone and Joint Disorders, 4th edn, W.B. Saunders, Philadelphia.

Sarzi-Puttini P. and Atzeni F. (2004) New developments in our understanding of DISH (diffuse idiopathic skeletal hyperostosis). Current Opinion in Rheumatology, 16: 287-292.

Scheinfeld M.H., Shifteh K., Avery L.L., Dym H., and Dym R.J. (2012) Teeth: what radiologists should know. RadioGraphics, 32: 1927-1944.

Singh R.B., Mengi S.A., Xu Y.-J., Arneja A.S., and Dhalla N.S. (2002) Pathogenesis of atherosclerosis: a multifactorial process. Experimental and Clinical Cardiology, 7: 40-53.

Slijkhuis W., Mali W., and Appelman Y. (2009) A historical perspective towards a non-invasive treatment for patients with atherosclerosis. Netherlands Heart Journal, 17: 140-145.

Steinbock R.T. (1976) Paleopathological Diagnosis and Interpretation: Bone Disease in Ancient Human Populations. Charles C. Thomas, Springfield, IL.

Thompson R.C., Allam A.H., Lombardi G.P., Wann L.S., Sutherland M.L., Sutherland J.D., Soliman M.A., Frohlich B., Mininberg D.T., Monge J.M., Vallodolid C.M., Cox S.L., Abd el-Maksoud G., Badr I., Miyamoto M.I., el-Halim Nur el-Din A., Narula J., Finch C.E., and Thomas G.S. (2013) Atherosclerosis across 4000 years of human history: The Horus study of four ancient populations. Lancet, 381: 1211-1222.

Tilley L. and Cameron T. (2014) Introducing the Index of Care: a web-based application supporting archaeological research into health-related care. International Journal of Paleopathology, 6: 5-9.

Viertel V.G., Intrapiromkul J., Maluf F., Patel N.V., Zheng W., Alluwaimi F., Walden M.J., Belzberg A., and Yousem D.M. (2012) Cervical ribs: a common variant overlooked in CT imaging. American Journal of Neuroradiology, 33: 21912194.

Waldron T. (2009) Palaeopathology. Cambridge University Press, Cambridge.

Wanek J., Papageorgopoulou C., and Rühli F.J. (2011) Fundamentals of paleoimaging techniques: bridging the gap between physicists and paleopathologists. In: Grauer A. (ed.), A Companion to Paleopathology. Wiley-Blackwell, Oxford, pp. 324-338. 